\title{
Cursing the darkness: Reactions to fibromyalgia
}

\author{
Manfred Harth MD FRCPC
}

Pats atients with fibromyalgia suffer from widespread pain and fatigue; their sleep is nonrefreshing (1-3); most experience headaches; and $48 \%$ may have migraine (4). Cognitive disturbances are common; other distressing and painful symptoms occur frequently and include irritable bladder, irritable bowel and vulvodynia (1-3). In one study of community cases of fibromyalgia (5), approximately one-half of the individuals examined were found to have high state and trait anxiety scores, and high scores for depression. Many patients with fibromyalgia are unable to engage in gainful employment; in one study in the United States, 26\% received disability payments, as did the same percentage in a study conducted in Canada (6). Kleinman et al (7) reported data obtained from approximately 700,000 employees from various large self-insured employers in the United States; employees with fibromyalgia incurred significantly higher total health benefit costs, and had a much higher number of days absent from work than employees without fibromyalgia; employees with fibromyalgia also had "significantly lower per-employee annual objective productivity" than employees without fibromyalgia.

In addition, patients with fibromyalgia have to shoulder a burden seldom borne by individuals with other medical conditions. Fibromyalgia sufferers are frequently not perceived as having a distressing condition. Their families, their friends and their coworkers are often skeptical of their symptoms or their functional impairment. Kool et al (8) used the term 'invalidation', which includes social rejection; they pointed out that invalidation includes not only a lack of understanding and denial, but also "lecturing and over protecting". A recent study reported on embitterment in 64 fibromyalgia patients who were employed; embitterment was the apparent result of a combination of invalidation and helplessness (9). Rodero et al (10) studied 250 patients with fibromyalgia using the Injustice Experience Questionnaire (IEQ), a measure of perceived injustice. They found that $47.2 \%$ of patients had high IEQ scores $(>30)$, which translated to a clinically relevant level of perceived injustice. IEQ scores were significantly associated with global function and pain catastrophizing (10).

Briones-Vozmediano et al (11) further explored the relationships between patients with fibromyalgia and their professional health care providers using a qualitative research approach; their report was published in the January/February 2013 issue of Pain Research and Management. Interviews were conducted with 12 patients and nine health professionals, of whom seven were physicians, one was a physiotherapist and one a psychologist. There were nine female and three male patients, ranging in age between 29 and 61 years; five of the 12 were inactive, unfit for work or on sick leave. A feeling of invalidation is expressed, for instance, by patient 7, who stated:

...They don't find anything wrong and they don't prescribe anything ... when you go up before the disability board they say 'who told you that' (11)

Another patient states:

When you try to explain all this simply to a doctor and he doesn't raise his eyes from his desk, or stop five minutes to listen to what you're saying, or I don't know, I think it's like a cold shower don't you? (11)

\section{Patient 12 perceived a professional as being cruel:}

And he started laughing at me. I turned around and said 'are you laughing at my pain?' and he said 'you don't want me to cry, do you?'

Patient complaints included delay and uncertainty in making a diagnosis, delays in referral to numerous specialists, the inefficacy of treatment and the expense of some treatments. The professionals agreed with the patients that they had difficulty in reaching a diagnosis. Professional 4, who was identified as a rheumatologist, states that "the problem is that there is no objective test to diagnose these patients". The professionals stated that "diagnosis was reached by elimination". They could not agree as to which complementary tests should be ordered. The professionals complained that "the lack of a known origin of the disease is reflected in the treatment prescribed". They stated that there was no effective specific treatment for fibromyalgia and questioned the effectiveness of treatment based on antidepressants and tranquilizers. They complained of not having sufficient time to dedicate to patients (professional 3). Interestingly, health professionals appear to have perceived themselves as taking an interest in their patients, while "in general, patients describe a lack of moral support from the professionals caring for them" (11). The relatively large number of occupational physicians in this study may be due to the idiosyncrasies of the Spanish health care system, in which occupational physicians are "responsible for evaluating the level of disability to assess requests for sick leave" (11). Thus, this article gives important insights into the real and perceived problems in the relationships between patients with fibromyalgia and their professional caregivers.

Fibromyalgia has been compared with the character portrayed by the late American comedian, Rodney Dangerfield, who complained: "I don't get no respect! No respect, no respect at all!". Ambivalence and ignorance appear to affect the performance of many physicians dealing with fibromyalgia. Some deny its very existence as a medical entity. Hadler (12), in a discussion of fibromyalgia, terms it "the medicalization of misery"; he suggests that "these people choose to be patients because they have exhausted their wherewithal to cope". Others regard fibromyalgia as a societal construct $(13,14)$. Hayes et al $(15)$ studied the views held by a large number of Canadian general practitioners and specialists with respect to fibromyalgia. Forty-one per cent of general practitioners and $37 \%$ of specialists reported unclear diagnostic criteria as a barrier to their identification of fibromyalgia; a total of $36 \%$ of general practitioners and $25 \%$ of specialists expressed doubt about their ability to diagnose fibromyalgia; $30 \%$ of general practitioners and $24 \%$ of specialists reported a lack of knowledge of treatment options in fibromyalgia; and $23 \%$ of general practitioners and $12 \%$ of specialists agreed with the statement that fibromyalgia patients were malingerers.

It is, therefore, not surprising that patients with fibromyalgia seeking help from their physicians may encounter hostility, skepticism, confusion and therapeutic nihilism. The experiences and attitudes described by Briones-Vozmediano et al (11) are not unique to one region of Spain. They exist in many countries. The situation, however, is not entirely bleak. First, much has become known about fibromyalgia. It is a disorder

Correspondence: Dr Manfred Harth, AIM Clinic, 458 Central Avenue, London, Ontario N6B 2E5. Telephone 519-432-1521,

fax 519-679-9658, e-mail mharthc593@rogers.com 
of unknown etiology, but its pathogenesis has become significantly clearer. Patients with fibromyalgia have a central pain-processing disorder, aggravated by an abnormally functioning descending pain inhibitory pathway; this has been demonstrated by a number of sophisticated neuroimaging and other techniques. Abnormally high concentrations of neurotransmitters, such as substance $\mathrm{P}$ and nerve growth factor, in the cerebrospinal fluid have been documented; genetic factors predisposing to this condition are being identified. All of this has been well outlined in several recent reviews (16-18). The statement that ignorance of the etiology of a condition precludes its treatment is incorrect. Conditions of unknown etiology are often treated successfully. Rheumatologists need only consider rheumatoid arthritis, ankylosing spondylitis and systemic lupus erythematosus. The diagnosis of fibromyalgia should not be a difficult one. The American College of Rheumatology Classification Criteria were published more than 20 years ago (19); some physicians have had difficulty in eliciting fibromyalgia trigger points on examination, thus presumably deterring them from making a diagnosis (20). The introduction of the American College of Rheumatology Preliminary Diagnostic Criteria, which avoid examination of trigger points, should now overcome that objection (21). The complaints voiced by several professionals in the study by BrionesVosmediano (11) reflect a common, but readily remediable, lack of confidence in their clinical skills. The symptoms of fibromyalgia can be easily elicited on history. The absence of confirmatory laboratory tests need not unduly intimidate physicians. Laboratory tests are not necessary in diagnosing other well-recognized painful conditions such as migraine and trigeminal neuralgia $(22,23)$.

Both patients and professionals in this study complained about the length of time that it took to confirm the diagnosis. Until recently, rheumatologists were believed to be the specialists most qualified to diagnose and treat fibromyalgia. This, however, is changing. Many rheumatologists now doubt that they should be responsible for the treatment of fibromyalgia $(24,25)$. A recent survey of Ontario rheumatologists shows that $71 \%$ believe that they should not retain ownership of fibromyalgia; only $60 \%$ were accepting new referrals for fibromyalgia in their practices and were managing patients with fibromyalgia; the great majority $(89 \%)$ believed that family physicians should be the main care providers for these patients (26). Family physicians can certainly learn how to diagnose fibromyalgia. In a study conducted in Israel (27), there was significant agreement between the diagnosis of fibromyalgia made by the referring family physician and the consultant rheumatologist.

In the Spanish study published in the January/February 2013 issue of Pain Research and Management (11), both patients and professionals were dissatisfied with the efficacy of treatment. A recent review of the

\section{REFERENCES}

1. Fitzcharles MA, Yunus MB. The clinical concept of fibromyalgia as a changing paradigm in the past 20 years. Pain Res Treat 2012;184835:1-8.

2. Arnold LM, Clauw DJ, McCarberg BH; for the Fibro Collaborative. Improving the recognition and diagnosis of fibromyalgia. Mayo Clin Proc 2011;86:457-64.

3. Bhadra P, Petersel D. Medical conditions in fibromyalgia patients and their relationship to pregabalin efficacy: Pooled analysis of phase III clinical trials. Expert Opin Pharmacother 2010;11:2805-12.

4. Evans RW, de Tommasso M. Migraine and fibromyalgia. Headache 2011;51:295-99

5. White KP, Nielson WR, Harth M, Ostbye T, Speechley M. Chronic widespread musculoskeletal pain with or without fibromyalgia: Psychological distress in a representative community adult sample. J Rheumatol 2002;29:588-94.

6. White KP, Speechley M, Harth M, Ostbye T. Comparing self-reported function and work disability in 100 community cases of fibromyalgia syndrome versus controls in London, Ontario: The London Fibromyalgia Epidemiology Study. Arthritis Rheum 1999;42:76-83.

7. Kleinman N, Harnett J, Melkonian A, Lynch W, Kaplan-Machlis B, Silverman SL. Burden of fibromyalgia and comparisons with osteoarthritis in the workforce. J Occup Environ Med 2009;51:1384-93.

8. Kool MB, van Middendorp H, Boeije HR, Geenen R. Understanding the lack of understanding: Invalidation from the perspective of the patient with fibromyalgia. Arthritis Rheum 2009;61:1650-6. longitudinal outcome of fibromyalgia showed that patients generally experienced continuing high levels of self-reported symptoms and distress, but that there was a slight trend toward improvement, especially with regard to pain (28); that study, however, may not reflect some recent changes in treatment. It has become clear that exercise (low impact aerobic and strengthening) can have significant beneficial effects (16). One patient interviewed in Briones-Vosmediano et al (11) complained about gymnasiums being expensive, but exercise can be pursued outside of a gymnasium. Cognitive behavioural therapy is also effective, although access to it may not be readily available. There is an increasing number of pharmacological agents, such as tricyclic antidepressants, certain serotonin and norepinephrine reuptake inhibitors, gamma-aminobutyric acid analogues, anti-epileptic agents (gabapentin and pregabalin) and analgesics such as tramadol, that have shown statistically significant efficacy in clinical trials, although, admittedly, such efficacy has only a modest effect size $(16,29)$. The various pharmacological agents and the various nonpharmacological interventions have been studied in isolation. However, it has been reported that the efficacy of monotherapy is limited, and that many patients require a combination of treatments (30); in practice, nonpharmacological interventions are often used with pharmacological interventions.

Fibromyalgia has been, and continues to be, a challenging problem. If family physicians are to be the primary diagnosticians and care providers, then it is important that they be well educated in the pathogenesis and diagnosis of fibromyalgia. Clearly, rheumatologists are becoming less willing to be the main caregivers, but if they do not want to retain ownership of fibromyalgia, they must participate actively and extensively in the educational efforts necessary to transfer its care to family physicians. It has been suggested that special multidisciplinary clinics be established to treat patients with fibromyalgia. Such clinics would be useful, but their objectives should be mainly those of performing research, assesssing and assisting with difficult cases and participating in effective educational programs for both patients and health care professionals. It is unrealistic to believe that such clinics could be responsible for the care of the great majority of the fibromyalgia population.

Progress in fibromyalgia has been painfully slow, but there has been and there continues to be progress. We may sympathize with those who curse the darkness, but we must keep in mind that lighting more candles is a much better strategy.

DISCLOSURES: Dr Harth has received a stipend from Pfizer Canada for acting as regional director for the Patient Partners program at the University of Western Ontario, London, Ontario, and is on the Medical Advisory Board for Pfizer Canada for Lyrica.

9. Blom D, Thomaes S, Kool MB, et al. A combination of invalidation from the work environment and helplessness is associated with embitterment in patients with FM. Rheumatology 2012;51:347.

10. Rodero B, Luciano JV, Montero-Marín J, et al. Perceived injustice in fibromyalgia: Psychometric characteristics of the Injustice Experience Questionnaire and relationship with pain catastrophising and pain acceptance. J Psychosom Res 2012;73:86-91.

11. Briones-Vozmediano E, Vives-Cases C, Ronda-Pérez E, Gil-Gonzaléz D. Patients' and professionals' views on managing fibromyalgia. Pain Res Manag 2013;18:19-24.

12. Hadler NM. "Fibromyalgia" and the medicalization of misery. J Rheumatol 2003;30:1668-70.

13. Hazemeijer I, Rasker JJ. Fibromyalgia and the therapeutic domain. A philosophical study on the origins of fibromyalgia in a specific social setting. Rheumatology 2003;73:507-15.

14. Wolfe F. Fibromyalgia wars. J Rheumatol 2009;36:671-78.

15. Hayes SM, Myhal GC, Thornton JF, et al. Fibromyalgia and the therapeutic relationship: Where uncertainty meets attitude. Pain Res Manag 2010;15:385-91.

16. Goldenberg DL, Clauw DJ, Fitzcharles MA. New concepts in pain research and pain management of the rheumatic diseases. Semin Arthritis Rheum 2011;41:319-34.

17. Clauw DJ, Arnold LM, McCarberg BH; FibroCollaborative. The science of fibromyalgia. Mayo Clin Proc 2011;86:907-11. 
18. Phillips K, Clauw DJ. Central pain mechanisms in chronic pain states - maybe it is all in their head. Best Pract Res Clin Rheumatol 2011;25:141-54

19. Wolfe F, Smythe HA, Yunus MB, et al. The American College of Rheumatology 1990 Criteria for the Classification of Fibromyalgia. Report of the Multicenter Criteria Committee. Arthritis Rheum 1990;33:160-72.

20. Harth M, Nielson WR. The fibromyalgia tender points: Use them or lose them? A brief review of the controversy. J Rheumatol 2007;34:914-22.

21. Wolfe F, Clauw DJ, Fitzcharles MA, et al. The American College of Rheumatology preliminary diagnostic criteria for fibromyalgia and measurement of symptom severity. Arthritis Care Res 2010;62:600-10.

22. Diener HC, Dodick DW, Goadsby PJ, Lipton RB, Olesen J, Silberstein SD. Chronic migraine - classification, characteristics and treatment. Nat Rev Neurol 2012;8:162-71

23. Zebenholzer K, Wöber C, Vigl M, Wessely P, Wöber-Bingöl C. Facial pain and the second edition of the International Classification of Headache Disorders. Headache 2006;46:259-63.

24. Shir Y, Fitzcharles MA. Should rheumatologists retain ownership of fibromyalgia? J Rheumatol 2009;36:667-70.
25. Larkin J. Should rheumatologists be managing fibromyalgia? Scott Med J 2012;57:43-4.

26. Ghazan-Shahi S, Towheed T, Hopman W. Should rheumatologists retain ownership of fibromyalgia? A survey of Ontario rheumatologists. Clin Rheumatol 2012;31:1177-81.

27. Shleyfer E, Jotkowitz A, Karmon A, Nevzorov R, Cohen H, Buskila D. Accuracy of the diagnosis of fibromyalgia by family physicians: Is the pendulum shifting? J Rheumatol 2009;36:170-3.

28. Walitt B, Fitzcharles MA, Hassett AL, Katz RS, Häuser W, Wolfe F. The longitudinal outcome of fibromyalgia: A study of 1555 patients. J Rheumatol 2011;38:2238-46.

29. Nüesch E, Häuser W, Bernardy K, Barth J, Jüni P. Comparative efficacy of pharmacological and non-pharmacological interventions in fibromyalgia syndrome: Network meta-analysis. Ann Rheum Dis 2012 Jun 27 (Epub ahead of print).

30. Calandre EP, Rico-Villademoros F, Rodríguez-López CM.

Monotherapy or combination therapy for fibromyalgia treatment? Curr Rheumatol Rep 2012 Jul 18 (Epub ahead of print). 


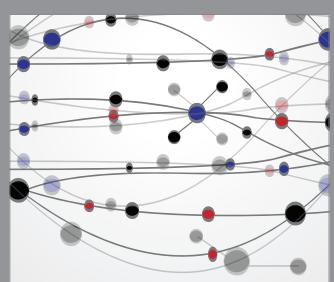

The Scientific World Journal
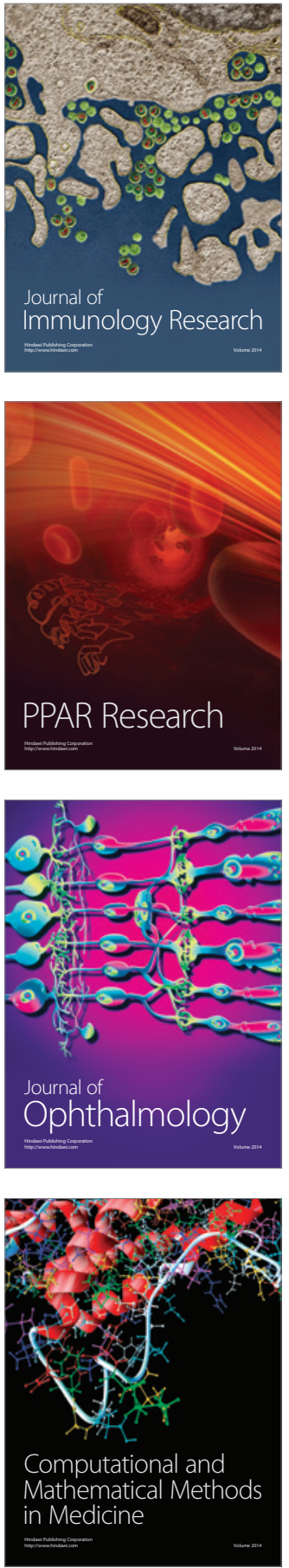

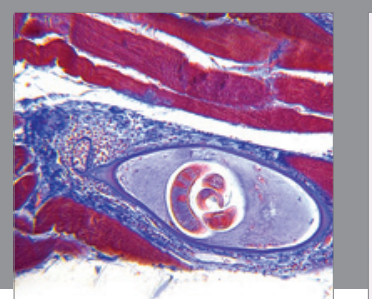

Gastroenterology Research and Practice

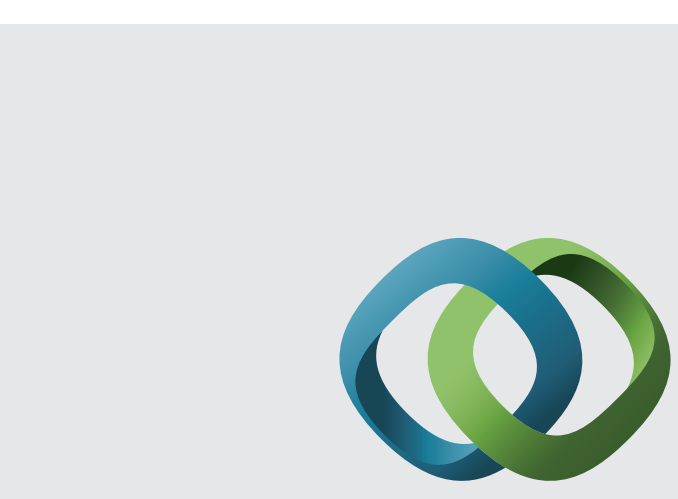

\section{Hindawi}

Submit your manuscripts at

http://www.hindawi.com
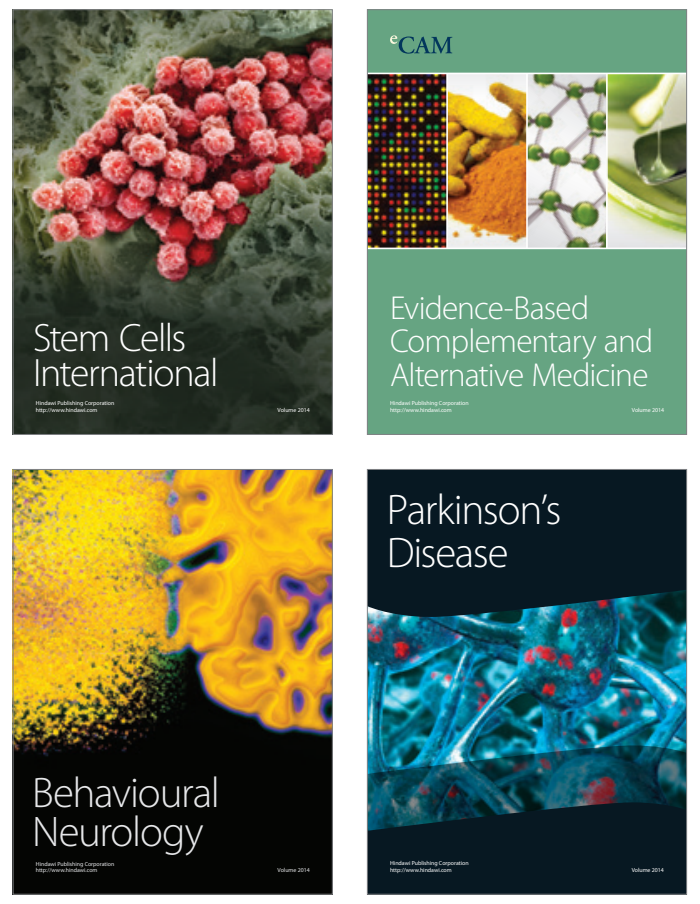
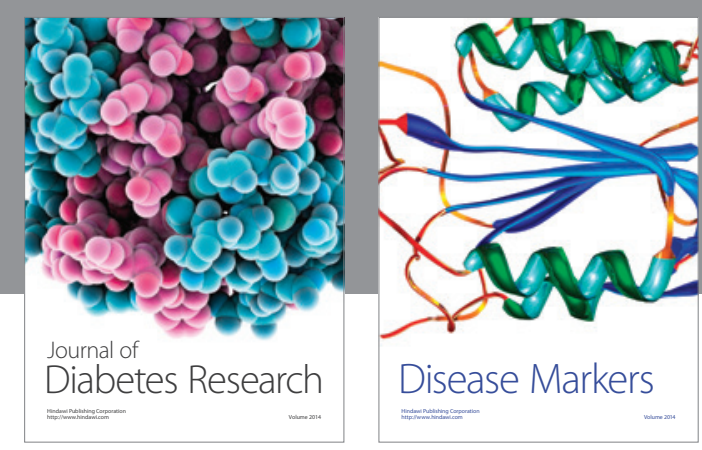

Disease Markers
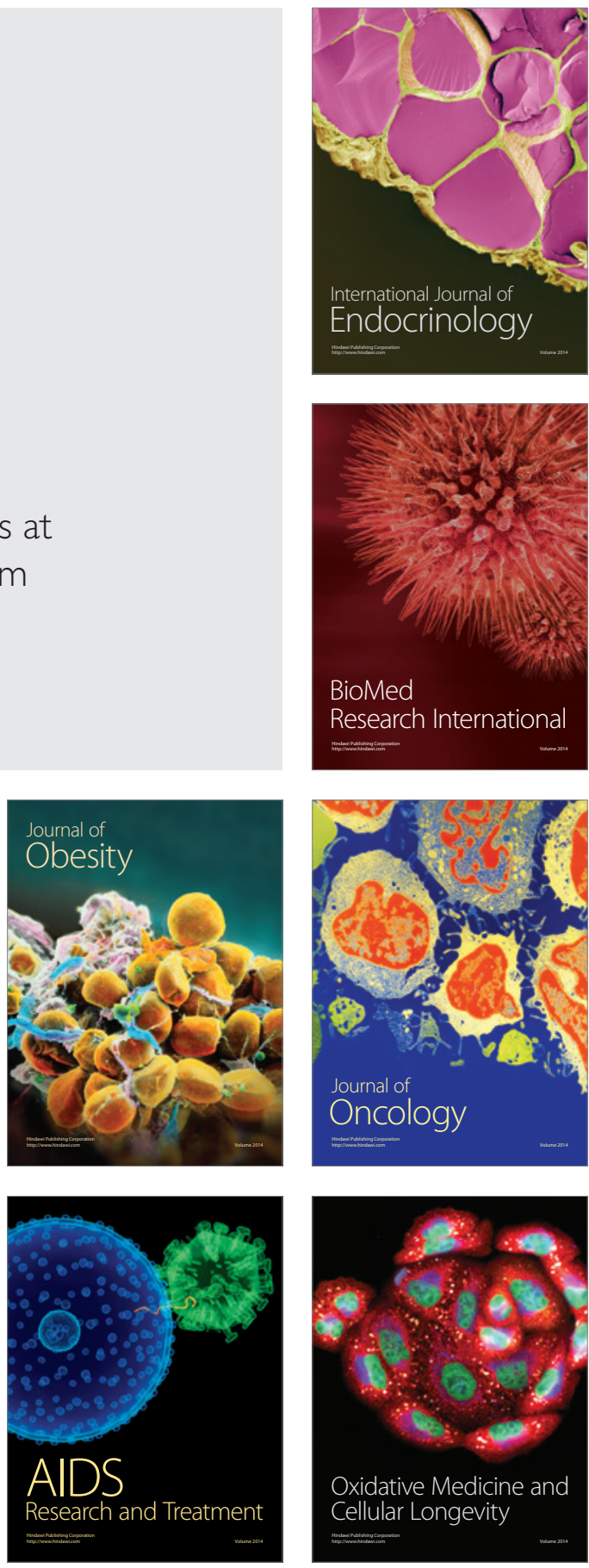